\title{
Do I belong here?: Describing identities of participation and non-participation in a contentious "board" meeting
}

\author{
Jared L. Durden \\ Physical Science, Ozarks Technical Community College, 1001 E. Chestnut Expy, Springfield MO, 65802 \\ Brant E. Hinrichs \\ Department of Chemistry and Physics, Drury University, 729 N. Drury Lane, Springfield, MO 65802
}

\begin{abstract}
In University Modeling Instruction, small groups work on a problem and then hold a student-led wholeclass discussion ("board" meeting) to develop consensus. In practice, some students regularly contribute more to these discussions than others, and end of course evaluations indicate not all students value them. To better understand those two phenomena, we had students in a university modeling classroom write about their experience after a particularly contentious board meeting. Because this highly participationist pedagogy requires students to be social while learning, we modeled the UMI classroom using Wegner's "Communities of Practice". In particular, to analyze student responses, we developed a preliminary code based on Wegner's social ecologies of identity framework describing student identities of participation and non-participation situated in the context of different modes of belonging within a community of practice. Student responses were sorted into three broad categories based on their descriptions of their experience during the board meeting. We developed our preliminary code by analyzing one student response from each of the three different categories. Initial coding of these three students' responses reveals a rich description of their different experiences during a contentious board meeting in the UMI classroom. Our intention is to continue coding the remaining student responses to further develop a robust description of this particular contentious board meeting. In building this descriptive model of student participation, we seek to develop a predictive model to inform professional development for instructors who teach with this pedagogy.
\end{abstract}

2019 PERC Proceedings edited by Cao, Wolf, and Bennett; Peer-reviewed, doi.org/10.1119/perc.2019.pr.Durden Published by the American Association of Physics Teachers under a Creative Commons Attribution 4.0 license. Further distribution must maintain attribution to the article's authors, cover page, and DOI. 


\section{INTRODUCTION}

The heart of University Modeling Instruction (UMI) $[1,2,3,4,5]$ is Modeling Discourse Management (MDM) [6], a learning-community approach that explicitly focuses on the epistemology of science. It is designed to help students understand through regular and sustained experience in the classroom that the conclusions of science are tentative and evolving and that knowledge and understanding of meaning are constructed and shared through dialogue with others. In MDM, students work in small groups to create a solution to the same problem on a 2'x 3' whiteboard. They then sit in a large circle with their whiteboards held facing in and conduct a student-led whole-class discussion ("board" meeting) with the goal of reaching consensus [7].

Such a highly participationist pedagogy is very effective for helping students learn physics $[4,8,9,10,11]$, but students do not seem to value all aspects of MDM equally [12]. In particular, we find that some students regularly and actively participate in board meetings, while others do not, even when they are directly or indirectly encouraged and/or prompted to do so. Comments from midterm feedback forms as well as anonymous end of course evaluations also often indicate that a portion of students prefer lecture and more direct instructor intervention, especially in the more contentious board meetings that take sustained time and/or effort to reach consensus.

Our research question asks how to model student participation in board meetings. In building a descriptive model of student participation in large group, we seek as well to develop a predictive model which could inform professional development for instructors who utilize such large group discussions. We begin by studying a contentious board meeting where small groups brought in very different initial ideas and the class struggled to negotiate between those ideas to achieve consensus [13]. Roughly only a third of the class actively contributed during the most challenging parts of the discussion and we wanted to better understand why.

We model a UMI classroom as a "Community of Practice" [14], which views learning as social participation - being an active participant in the practices of a social community. The social community in a UMI classroom consists of the students and instructor, while the practices consist of model development, deployment, and refinement, as well as small group work and board meetings.

In the rest of this paper, we briefly describe (i) the context for this study, (ii) our methodology, (iii) Wenger's social ecology of identity, which relates student identities of participation and non-participation in the context of three modes of belonging, (iv) our theoretical framework as coding scheme $(\mathrm{v})$ initial results of applying this code to analyzing three student reflective writing responses after a particularly contentious board meeting, and end with (vi) a discussion of possible meanings of these initial results.

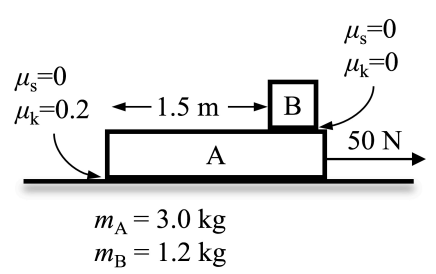

FIG. 1. Diagram students were given for the two stacked blocks problem. Used with permission of Dwain Desbien.

\section{CONTEXT}

The context for this study is an introductory calculusbased physics course at Drury University taken by all science majors. Students worked on a problem called "Two Stacked Blocks." It is a goal-less problem [15] in which students are shown the diagram in Figure 1 and asked to find everything they possibly can. This was their first encounter with objects with mass that interact vertically. The board meeting was contentious because the class struggled with accounting for how block B effected block $\mathrm{A}$ and how to model both blocks to allow for $\mathrm{B}$ to eventually slide off A [13]. The board meeting for this was early in the second semester, Spring 2017, so the class already had extensive experience with UMI. The discussion lasted about forty minutes.

Because the board meeting was contentious, students were given a reflective writing assignment: Did you participate very much in that part of the discussion? If so, why? If not, why not? Please explain.

\section{METHODOLOGY}

Student responses to the reflective writing questions indicated they experienced the contentious board meeting in very different ways. Therefore, our study takes a phenomenographic approach by investigating the qualitatively different ways in which students experienced or thought about the large group discussion and their participation [16].

Based on their written responses, we placed students into three broad categories: eleven who actively participated, five who did not actively participate because they thought others were doing a good enough job, and seven who did not actively participate and expressed a negative view of the discussion. The data presented in this paper comes from our preliminary coding of one student from each of the three categories; Student 1, Student 2, and Student 3, respectively [17].

\section{THEORETICAL FRAMEWORK}

The center of Figure 2 shows Figure 9.1 "Social ecology of identity" from pg. 190 of Wenger [14]. The far left and far right sides of Figure 1 show how we have interpreted his categories in the context of a UMI physics classroom. 


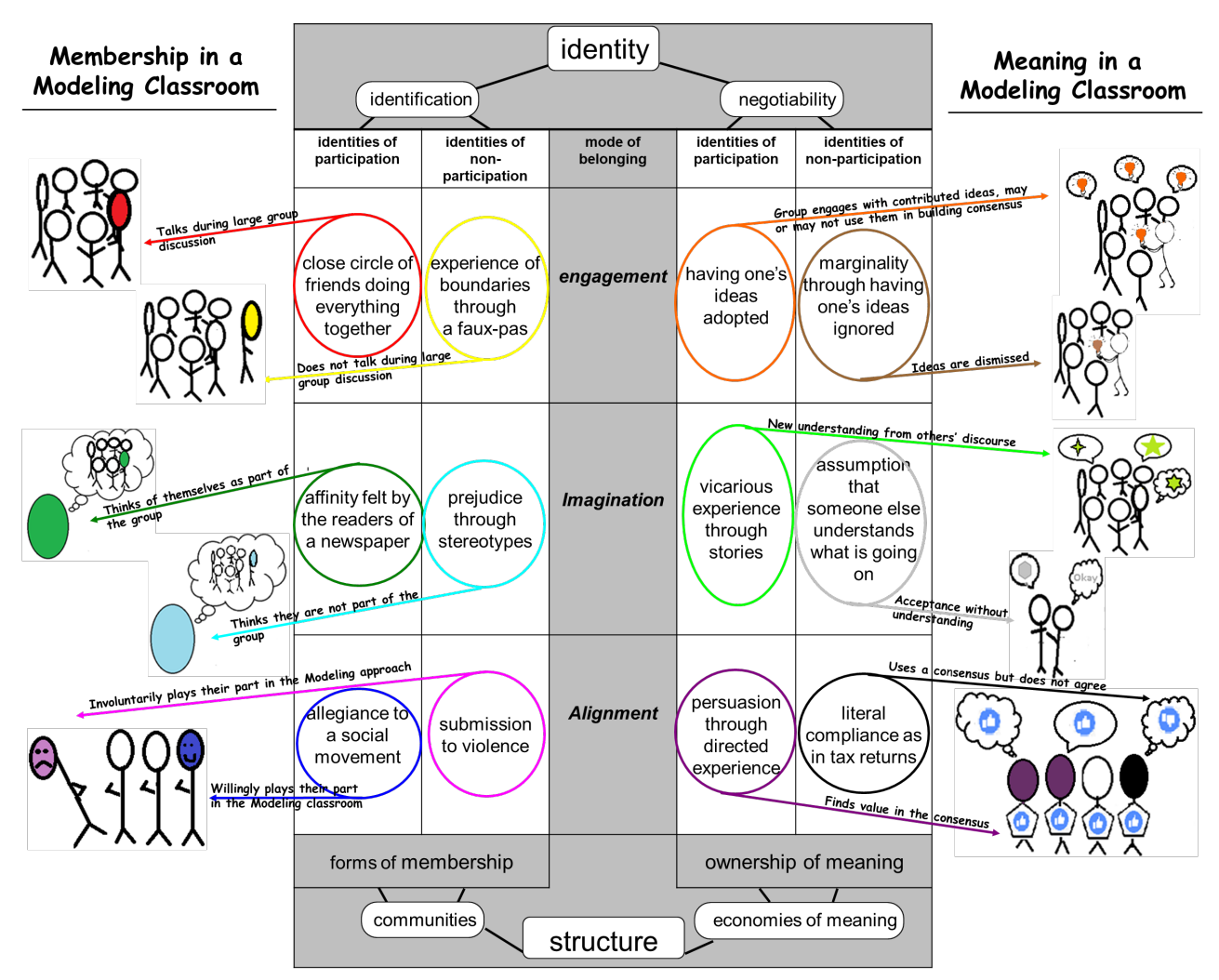

FIG. 2. Wenger's social ecology of identity figure interpreted in the context of a UMI classroom. The black, white and grey portions of the central section reproduce exactly Fig. 9.1 from pg. 190 of [14]. The far left- and right-hand sides and all color are our interpretations. The twelve categories of our coding scheme come from the twelve white boxes that are circled in color. See Section V. for details of all twelve. Fig. 9.1 used with permission of the author.

The chart outlines from top to bottom the two processes, Identification (i) and Negotiability (n), by which identity is formed through practice within a community. The 3 modes of belonging listed down the center of the chart, Engagement (E), Imagination (I), and Alignment (A), are different sources of Identification and/or Negotiability. They provide the context to situate the experiences of participation (P) and non-participation (N) that inform forms of membership and economies of meaning within a community of practice.

Thus, there are 12 possible categories created by this framework that qualitatively describe a students' experience as it relates to practice within the community. Our coding scheme interprets student writing as it corresponds to the 12 possible categories in the context of a board meeting in a (university) modeling classroom.

\section{EXEMPLARS OF CODING SCHEME}

\section{A. Forms of membership codes (i)}

In this section we provide preliminary examples from student writing for the six contexts on the left side of the chart whereby students construct identities through the process of identification (i). We interpret these examples as pertaining to the social aspects of the board meeting.

\section{Engagement $(E)$}

Identification through engagement is about "doing" within the community. Students' actions can then translate to association or disassociation in respect to community membership.

\section{a. Identification, Engagement, Participation (iEP)}

Student 1: "For both of these arguments, I think I participated a good amount,"

Student 2: "I didn't participate that much, but I was paying attention."

Both students participate with varying degrees. Student 2 participates mostly passively but is actively involved through "paying attention" which we interpret as association.

\section{b. Identification, Engagement, Non-participation (iEN)}

Student 3: "I did not participate in this part of the discussion because I felt that I would be shot down"

The student does not participate because of a perceived 
social boundary, possibly due to a previous experience. We interpret this as disassociation.

\section{Imagination (I)}

Identification through imagination "takes the process beyond engagement" [12]. Students' images of and assumptions about the community inform their perceptions of mutuality or differentiation with groups in the classroom.

\section{a. Identification, Imagination, Participation (iIP)}

Student 1: "Our job as students is to take the information given and simplify it in a way that makes sense to us and allows us to arrive at the correct answer.

Student 3: "I had already accepted the fact that myself (and my small table group) was wrong before the end of discussion"

Student 1's use of "Our" indicates an affinity with other students in the classroom. Student 3 takes ownership for a wrong answer and shares that responsibility with all group members. This indicates they see themselves as members of a group of students in the classroom.

\section{b. Identification, Imagination, Non-Participation (iIN)}

Student 3: "They believed firmly enough in their way of thinking that they would shoot down any other explanation of how the situation could be thought about".

The use of "They" identifies a group conceived by student 3 but in which student 3 is not a member. To student 3, "They" is the opposition from which student 3 has distanced themself.

\section{Alignment $(A)$}

Identification through alignment is the process through which students choose to or are forced to invest and coordinate their energies to achieve common purpose.

\section{a. Identification, Alignment, Participation (iAP)}

Student 1: "Our job as students is to take the information given, and simplify it in a way that makes sense to us"

Student 2: "I was agreeing with everything he was saying"

Student 3: "I feel that the rules taught in this class period would have been better shared in an atmosphere where variant ideas were not shot down."

Students 1 and 2 are describing key requirements of the UMI classroom. Simplification and consensus building are two essential components of model development and deployment that are explicitly and regularly practiced by students in the UMI classroom. We interpret Student 3's description of a more productive "atmosphere" as a reference to the dispositions [19] students need to be actively practicing in order to communicate effectively and build consensus in a highly participationist UMI classroom. All three students are expressing that they value and are internally motivated to fulfill what they view as the requirements for membership in the community.

\section{b. Identification, Alignment, Non-Participation (iAN)}

We did not find any examples of iAN in these three students' writing. However, we would like to present an anecdotal example from classroom field notes. During a large group discussion, the instructor asked a group to start with their models and assumptions, which is a class norm. The student presenting responded: "Why?" This is an example of iAN because despite having their models and assumptions clearly written at the top of their whiteboard, the student obviously did not find value in them.

\section{B. Ownership of Meaning codes (n)}

These are preliminary examples from student writing for the six contexts on the right side of the chart whereby individuals construct identities through negotiability (n). We interpret these examples as pertaining to the ideas discussed during the board meeting.

\section{Engagement (E)}

Negotiability through engagement involves the production of proposals for meaning. Wenger also includes the adoption of proposals of meaning to be equally important as production, but we do not. This is because in a science classroom, less useful ideas still contribute to discourse despite not being adopted. Therefore, we interpret a statement as being nEP if the students' ideas are discussed.

\section{a. Negotiability, Engagement, Participation (nEP)}

Student 2: "Wally said what I was thinking"

Student 2's ideas are informing the discourse even though they are not saying them in the board meeting.

\section{b. Negotiability, Engagement, Non-Participation (nEN)}

Student 3: I did not participate in this part of the discussion because I felt that I would be shot down just like any other variant of what the minority believed.

We interpret "I" in "I would be shot down" as referring to student 3's ideas because of the comparison made to the "variant" of what others believed. Therefore, we assume Student 3 equates themself with their ideas. Student 3 believes their ideas will not be engaged with by a subset of the group that they are referring to as the "minority". They do not participate possibly because they witnessed similar ideas being disregarded previously. 


\section{Imagination (I)}

Negotiability through imagination allows students to shape their understanding of meaning through vicarious experience of "playing" with the ideas of others.

\section{a. Negotiability, Imagination, Participation (nIP)}

Student 1: "I see the other side's argument about how adding a width would make the problem realistic,"

Student 2: "The main reason I didn't was because Wally was doing a good job of explaining why we wouldn't include mass of $B$ in the equation."

Both students refer to ideas constructed by other students and both students make statements that suggests those ideas informed their own construction of meaning in the community.

\section{b. Negotiability, Imagination, Non-Participation (nIN)}

Student 3: "I feel that the rules taught in this class period would have been better shared in an atmosphere where variant ideas were not shot down."

Student 3 describes knowledge as external by describing knowledge as "taught" or "shared" rather than mutually negotiated. Someone else has the knowledge and it must be given to student 3 .

\section{Alignment}

Negotiability through alignment determines how a student's construction of meaning comes to coordinate with the norms of the community.

\section{a. Negotiability, Alignment, Participation (nAP)}

Student 1: "In physics, especially when working with models, I have learned that the best way to go about a problem is to simplify it as much as possible and stay in agreement with the models"

Student 2: "The main reason I didn't was because Wally was doing a good job of explaining why we wouldn't include mass of $B$ in the equation."

Student 3: "I had already accepted the fact that myself (and my small table group) was wrong before the end of discussion"

Student 1 describes what they have learned, which is a process that took time and persuaded them to coordinate their ideas with class norms of simplification and model deployment. Students 2 and 3 make statements about their consensus with the ideas given by other students, which is consistent with the class norms. Student 2 also references
TABLE I: Histogram of codes from the three students' writing. This table is based on the layout of the center of Fig 2.

\begin{tabular}{|c|c|c|c|c|c|c|c|c|c|c|c|c|c|c|}
\hline & \multicolumn{4}{|c|}{ Student 1} & \multicolumn{5}{|c|}{ Student 2} & \multicolumn{5}{|c|}{ Student 3} \\
\hline $\mathrm{P}$ & $\mathrm{N}$ & & $\mathrm{I}$ & $\mathrm{N}$ & $\mathrm{P}$ & $\mathrm{N}$ & & & $\mathrm{N}$ & $\mathrm{P}$ & 1 & & & $\mathrm{~N}$ \\
\hline 6 & 1 & E & 2 & & 4 & & $\mathrm{E}$ & . & & & 2 & $\mathrm{E}$ & & 1 \\
\hline 7 & 1 & I & 5 & & & & I & . & & 1 & 5 & I & & 1 \\
\hline 4 & & A & 5 & & 3 & & A & & & 1 & & A & 1 & 2 \\
\hline
\end{tabular}

the class norm of explicitly coordinating representations (object B is not in the system).

\section{b. Negotiability, Alignment, Non-Participation (nAN)}

Student 3: "Towards the backside of this specific circumstance, I was so frustrated with some of my classmates that I did not WANT to believe what they were arguing for to be true."

Student 3 does not say they won't reach consensus or will not use the ideas being constructed in the whole class discussion. Instead, they express a desire not to, but not based on the validity of the ideas themselves. We interpret the stating of such a desire is not the same as actually acting on it. We assume this means the student will still use the idea, but begrudgingly.

\section{DISCUSSION}

Using Wenger's 12 categories has allowed for a rich description of different student experiences in a board meeting in the UMI classroom. Qualitatively, we see Student 3 constructing identities of participation even when expressing frustration in the large group discussion. We also see Student 2 less active in the board meeting but clearly identifying as a member of the UMI classroom. Furthermore, Table 1 quantitatively reveals an experience "finger-print" unique to each student. For example, Student 1 has extensive examples of (P) in each mode of belonging for both (i) and (n) but limited examples of (N). In stark contrast, Student 3 has extensive examples of (N) in each mode of belonging for both (i) and (n) but limited examples of (P).

Together, both aspects inform our understanding of how students can experience the same phenomenon so differently. For example, Student 1 discusses their ideas as external to themself and is flexible during the discussion, allowing them to negotiate meaning throughout the conversation. In contrast, Student 3 does not separate themself from their ideas and sees contrasting views as a personal attack, which discourages them from participating.

\section{ACKNOWLEDGMENTS}

We thank Carly Petersen Durden for critical review of the manuscript, and our families for their love, encouragement, and support. 
[1] D. Hestenes, "Toward a modeling theory of physics instructtion" Am. J. Phys. 55, 440-454 (1987).

[2] M. Wells, D. Hestenes, and G. Swackhamer, "A modeling method for high school physics instruction", Am. J. Phys. 63, 606-619 (1995).

[3] I. A. Halloun, Modeling Theory in Science Education (Berlin: Springer) (2004).

[4] E. Brewe, "Modeling theory applied: modeling instruction in introductory physics", Am. J. Phys. 76 (12), 1155-1160 (2008).

[5] E. Brewe and V. Sawtelle, "Modelling instruction for university physics: examining the theory in practice", Eur. J. Phys. 39054001 (2018).

[6] D. M. Desbien, Modeling discourse management compared to other classroom management styles in university physics, Ph.D. thesis, Arizona State University, 2002.

[7] B. E. Hinrichs, "Sharp Initial Disagreements Then Consensus in a Student Led Whole-Class Discussion", 2013 PERC Proceedings [Portland, OR, July 17-18, 2013], edited by P. V. Engelhardt, A. D. Churukian, and D. L. Jones, doi:10.1119/perc.2013.pr.033.

[8] D. Hestenes, "Modeling games in the Newtonian world," Am. J. Phys. 60, 732-748, 1992.

[9] Hake, R. R. "Interactive-engagement versus traditional methods: A six-thousand-student survey of mechanics test data for introductory physics courses ." Am. J. Phys. 66, 64 (1998).

[10] E. Etkina, and A. Van Heuvelen, "Investigative Science Learning Environment - A Science Process Approach to Learning Physics," in Research-Based Reform of University Physics, edited by E. F. Redish, and P. J. Cooney, 2007, vol. 1.

[11] Meltzer, D. E., Thornton, R. K., "Resource Letter ALIP-1: Active-Learning Instruction in Physics", Am. J. Phys. 80, 478 (2012).

[12] L. Deslauriers, L. S. McCarty, K. Miller, K. Callaghan, and G. Kestin, "Measuring Actual Learning Versus Feeling Of Learning In Response To Being Actively Engaged In The Classroom", PNAS 116 (39) pg 19251 (2019).

[13] D. T. Brookes, B. E. Hinrichs, Social Positioning Correlates with Consensus Building in Two Large Group Meetings, 2019 PERC Proceedings [Provo, UT, July 24-25, 2019], edited by Y. Cao, S. Wolf, and M. Bennett.

[14] E. Wenger, Communities of Practice: Learning, Meaning, and Identity, Cambridge University Press, 1998.

[15] P. D'Alessandris, The Development of Conceptual Understanding and Problem-Solving Skills through Multiple Representations and Goal-less Problems, AAPT Announcer 24(4), 47 (1994)

[16]Richardson, J.T.E. (1999). 'The Concepts and Methods of Phenomenographic Research', Review of Educational Research 69, 53-82.

[17] Through the rigorous process of constant comparison [18], we engaged in multiple iterative cycles of each co-author independently reading student writing and assigning codes, comparing those two codings with each other, making appropriate changes to the interpretation of the codes, and returning to the student writing.
[18] A. L. Strauss, Qualitative Analysis For Social Scientists, Cambridge University Press, Cambridge, England, 1987.

[19] (i) Desire to communicate and share ideas with others, (ii) willingness to take risks with one's ideas, (iii) willingness to live with ambiguity, (iv) respect for and interest in the ideas of others. These were developed by Dewey Dykstra for use in his physics course for pre-service teachers. He got the first three from Joan Rubin, a colleague in language learning. He came up with the fourth one after using the first three for a while. 